\title{
Biotechnology and pasta-making: lactic acid bacteria as a new driver of innovation
}

\author{
Vittorio Capozzi ${ }^{1,2}$, Pasquale Russo ${ }^{1,2}$, Mariagiovanna Fragasso ${ }^{3}$, Pasquale De Vita ${ }^{3}$, Daniela Fiocco ${ }^{4}$ and \\ Giuseppe Spano ${ }^{1 *}$
}

' Molecular Microbiology, Department of Food Science, Foggia University, Foggia, Italy

2 Promis Biotech srl, Facoltà di Agraria, Università degli Studi di Foggia, Foggia, Italy

${ }^{3}$ CRA Cereal Research Centre, Foggia, Italy

${ }^{4}$ Department of Biomedical Sciences, Foggia University, Foggia, Italy

\section{Edited by:}

Eric Altermann, AgResearch Ltd, New Zealand

\section{Reviewed by:}

Xiangzhen Li, University of Illinois at Urbana-Champaign, USA

Yu-Tzu Huang, Chung Yuan Christian University, Taiwan

\section{*Correspondence:}

Giuseppe Spano, Department of Food Science, Foggia University, via Napoli

25, Foggia 71122, Italy.

e-mail:g.spano@unifg.it
Cereals-derived foods represent a key constituent in the diet of many populations. In particular, pasta is consumed in large quantities throughout the world in reason of its nutritive importance, containing significant amounts of complex carbohydrates, proteins, B-vitamins, and iron. Lactic acid bacteria (LAB) are a heterogeneous group of bacteria that play a key role in the production of fermented foods and beverages with high relevance for human and animal health. A wide literature testifies the multifaceted importance of $L A B$ biotechnological applications in cereal-based products. Several studies focused on LAB isolation and characterization in durum wheat environment, in some cases with preliminary experimental applications of $L A B$ in pasta-making. In this paper, using sourdough as a model, we focus on the relevant state-of-art to introduce a LAB-based biotechnological step in industrial pasta-making, a potential world driver of innovation that might represent a cutting-edge advancement in pasta production.

Keywords: lactic acid bacteria, pasta, sourdough, quality, microbial cell factories

\section{INTRODUCTION}

Wheat-derived foods (e.g., pasta, bread, noodles) represent key constituents in the diet of many populations. In particular, pasta is largely consumed throughout the world in reason of its gastronomic and nutritive importance (Antognelli, 1980), as it contains significant amounts of complex carbohydrates, proteins, B-vitamins, and iron. In 2010, about 12.8 million tonnes of pasta have been produced worldwide. The world pasta production is dominated by the European Union and American countries, even if states like Egypt, Turkey, Japan, and India are also considered important producers (http://www.pasta.unfpa.org). In Europe and North America, the raw material for pasta products is generally durum wheat. The use of durum semolina leads to higher rheological properties of the dough, as well as greater color and cooking quality of the product (Troccoli et al., 2000). However, it is possible to employ non-durum wheat ingredients to produce specifically blended pasta (Fuad and Prabhasankar, 2010). Conventional pasta can be enriched, supplemented, or fortified. In recent years, several ingredients and additives have been designed to enhance the quality of pasta, by improving nutritional parameters, palatability, and overall product quality (Fuad and Prabhasankar, 2010). According to de Noni and Pagani (2010), the more advanced innovations in pasta manufacturing have been focused on optimizing the drying process. Conversely, less attention has been paid to evaluating the consequences of the drying process: heat damaged molecules and pasta constituents can affect the sensorial and the nutritional quality of the finished product. With this concern, the authors (de Noni and Pagani, 2010) underlined the importance of promising biotechnological innovations to solve this critical issue in pasta quality. With this goal and with a more general aim, even if it is well known that pasta products do not require any microbial bio-process to achieve the final product, we highlight the impact of the potential biotechnological applications of lactic acid bacteria (LAB) in pasta-making process. LAB constitute a heterogeneous group of bacteria that play a key role in the production of fermented foods and beverages, with high relevance for human and animal health. A wide literature testifies the multifaceted existing importance of LAB biotechnological applications in cereal-based products (Salminen et al., 2004). Several studies have focused on LAB isolation and characterization in durum wheat environment, in some cases with experimental applications of LAB in pasta-making (Corsetti et al., 2001, 2007; di Cagno et al., 2005; Ricciardi et al., 2005; Valerio et al., 2009; De Angelis et al., 2010; Russo et al., 2010; Capozzi et al., 2011).

This review will briefly describe the existing, available knowledge to introduce a LAB-based biotechnological step as a driver of innovation in pasta production. Naturally, the aim of this paper is not to be exhaustive of all the possible applications, but to clearly illustrate the principal determinants and insights involved. In particular, the proposed biotechnological applications open new opportunities in enhancing functional and nutritional pasta quality, and texture of gluten-free pasta products.

\section{LAB BIOTECHNOLOGICAL IMPORTANCE IN SOURDOUGH ENVIRONMENT ECOLOGICAL FACTORS AND BIODIVERSITY}

To introduce the possible industrial applications of LAB potential in pasta products, we briefly present the sourdough environment 
as the closest ecological and technological environmental model. Sourdough, essentially a mixture of cereal flour and water, is reported to be a metabolically active dough featuring a heterogeneous microflora, mainly represented by LAB and yeasts (Vogel et al., 1999; De Vuyst and Neysens, 2005; Corsetti and Settanni, 2007; De Vuyst and Vancanneyt, 2007; De Vuyst et al., 2009).

In regards to the microecology of durum wheat sourdough, Corsetti et al. (2001) analyzed 25 durum wheat sourdoughs from the South of Italy (Apulia) and identified a bacterial population composed by $30 \%$ of L. sanfranciscensis, $20 \%$ Lactobacillus alimentarius, $14 \%$ L. brevis, 12\% Leuconostoc citreum, 7\% L. plantarum, 6\% Lactococcus lactis subsp. lactis, 4\% L. fermentum and Lactobacillus acidophilus, 2\% Weissella confusa, and 1\% Lactobacillus delbrueckii subsp. delbrueckii (Corsetti et al., 2001). Ricciardi et al. (2005), in the durum wheat sourdough used for preparation of Altamura bread, found $88 \%$ of facultatively heterofermentative LAB (L. plantarum, Lactobacillus paracasei, Lactobacillus casei) and $12 \%$ of heterofermentative LAB (L. brevis, Leuconostoc mesenteroides).

\section{THE METABOLIC ARENA}

Studies by Gobbetti et al. (2005), Gänzle et al. (2007), and De Vuyst et al. (2009) provide excellent overviews on the metabolism of sourdough LAB. Several reports underline the strong connection between the microbial diversity of the sourdough ecosystems and the end-product metabolites (De Vuyst and Neysens, 2005; Corsetti and Settanni, 2007; De Vuyst and Vancanneyt, 2007; Paramithiotis et al., 2007; Scheirlinck et al., 2007; Van der Meulen et al., 2007; De Vuyst et al., 2009; Zhang and Gänzle, 2010; Ravyts and De Vuyst, 2011).

With respect to carbohydrate metabolism, LAB can be divided into three groups: obligate homofermenters, obligate heterofermenters, and facultative heterofermenters. Homofermentation of hexoses procedes via the Emden-Meyerhoff pathway, with the final conversion of pyruvate into lactate. Heterofermenters obtain energy to grow from the catabolism of sugar via the pentose phosphate pathway, producing lactic acid, acetic acid, ethanol, and $\mathrm{CO}_{2}$. Facultative heterofermenters degrade hexose like homofermenters, but possess an inducible phosphoketolase and thus are able to ferment pentose to lactic acid and acetic acid.

Almost all LAB have numerous (4 up to 14 amino acids) auxotrophies, consequently LAB depend on the degradation of proteins (Gobbetti et al., 2005). The proteolytic system acts at different levels by means of (i) extracellular proteinase, (ii) specific transport systems for di/tri-peptides and oligopeptides, and (iii) intracellular peptidases (Gobbetti et al., 2005).

Besides carbohydrate and peptide utilization, sourdough LAB possess numerous metabolic activities of interest during sourdough fermentation (Corsetti and Settanni, 2007).

\section{LAB BIOTECHNOLOGICAL POTENTIAL IN PASTA-MAKING PROCESS COMPATIBILITY}

A primary issue to assess the potential industrial exploitation is to define a LAB employ in pasta manufacturing which is coherent with the required final quality of pasta products. According to Bevilacqua et al. (2007), we briefly overview the principal stages of pasta production. Most pasta is manufactured by continuous, high capacity extruders, in which kneading and extrusion are performed as a single operation. As said in the introductory section, pasta manufacturers prefer semolina as principal raw material, which consists of fine particles of uniform size and produces the highest quality pasta product. The water used should meet the requirements for drinking water. The durum wheat is subjected to grinding phase, resulting in semolina and sub-products. Semolina is used for pasta, while sub-products are utilized for cattle feed. The industrial production begins with the dosing phase: about $0.3 \mathrm{~kg}$ of water is added for each kilogram of semolina, up to a final humidity content of about $35 \%$, and the mixture is centrifuged at an average speed of $8,000 \mathrm{rpm}$. In the subsequent kneading phase, several paddle wheels knead the mixture in a series of $\mathrm{W}$-shaped basins. The obtained dough is transferred to the extruder. In the drawing phase, the mixture is pressed and wiredrawn under a pressure with values ranging from 4 to 10 bar. The drying phase, the most difficult and critical step to control, consists of a flow of hot air at a maximum temperature of $80^{\circ} \mathrm{C}$ that heats the pasta, thus reducing progressively its humidity from a 30 to a $12.5 \%$ value.

To the best of our knowledge, in literature there are two main approaches proposed for the potential application of LAB in pasta manufacture (di Cagno et al., 2005; Capozzi et al., 2011). di Cagno et al. (2005) performed a fermentation of durum wheat semolina with selected lactobacilli to produce pasta with the goal to potentially decrease gluten intolerance. A pool of selected LAB was used to ferment durum wheat semolina under liquid conditions, the final product was freeze-dried, mixed with buckwheat flour at a ratio of 3:7, and used to produce pasta product. This approach allows a real sourdough-like phase, with the advantages of a complete use of LAB potentialities. However, the freezing-dry process probably leads to a substantial increase of pasta production costs. Recently, a selected mix of LAB was used to produce vitamin B2enriched pasta (Capozzi et al., 2011). In particular, two selected spontaneous riboflavin-overproducing variants of $L$. plantarum were added up to $10^{7} \mathrm{CFU} / \mathrm{g}$. The pre-fermentation step at $30^{\circ} \mathrm{C}$ was performed at two water content levels (42 and $60 \%$ for $16 \mathrm{~h}$ ). After the pre-fermentation step, the remaining semolina fraction was added to perform a classical pasta-making procedure. This approach introduces a novel and direct exploitation of LAB with biotechnological potential in pasta-making.

The big effort remains to couple sourdough technology with pasta-making technology in a new innovative application: a LABbased biotechnological step in pasta production. A critical question is represented by the end-products of microbial carbohydrate catabolism. In the case of heterofermentative $\mathrm{LAB}$, the massive production of $\mathrm{CO}_{2}$ may lead to production of bubbles in the food matrix. Effectively, in most modern pasta plants the last W-shaped basin works under vacuum conditions, so to remove air bubbles from the dough before extruding. This device probably will help to overcome the problem of small bubbles produced by LAB that might diminish the mechanical strength and give the finished product a white and chalky appearance. However, in our opinion, homofermentative and facultative heterofermentative bacteria remain the best candidates for starter formulation. Other disadvantages might be connected to the changes introduced by LAB biochemisms (e.g., acidification activity) and to the consequent impact on pasta technological quality. With this regard, Capozzi 
et al. (2011) did not detect any change in pasta cooking quality when L. plantarum were used in the pasta-making procedure. However, in reason of the numerous strain-dependent characteristics, it is strongly suggested to assess pasta quality in reason of the microbial resources employed. Obviously, this biotechnological step requires additional time and costs in the production process, thus each application requires a tailored cost-benefit analysis.

Concerning microbial dynamics, Russo et al. (2010) studied the dominant LAB directly during a pasta manufacturing process. The majority of strains were identified as belonging to Pediococcus pentosaceus and Enterococcus faecium species. The remaining strains were characterized and assigned to Weissella confusa, Pediococcus acidilactici, L. mesenteroides, L. citreum, L. fermentum, and L. plantarum species. During the technological steps, an increase of LAB population was observed from kneading to extrusion, followed by a continuous decrease, probably in reason of the raising temperature encountered in extrusion and pre-heating.

A microbial diversity is evident comparing semolina sourdough (Corsetti et al., 2001; Ricciardi et al., 2005; see Ecological Factors and Biodiversity) and semolina processed in pasta-making (Russo et al., 2010). Whereas it appears difficult to address all the changes to process conditions, in fact it is important to consider also the original microbiota in the semolina, the diverse polarity in dominant population clearly indicates the significance to consider the different environmental determinants during pasta-making with respect to a general sourdough model. This underlines the importance to calibrate the potential biotechnological impact of specific LAB biotypes and to consider the dominance of starter cultures for these particular applications. Probably the abiotic stressors typical of pasta-making (e.g., temperature, humidity, pressure) have a role in shaping the microbial population during the process.

Besides, from a metabolic perspective, it is crucial to remark that differences exist in the macronutrient composition of common wheat (Triticum aestivum L.) and durum wheat (Triticum durum Desf.), and that it will be interesting to assess how these differences influence LAB sourdough metabolism.

\section{QUALITY IMPROVEMENT}

In the food sector, LAB-driven fermentations are performed to obtain safe and shelf stable food products with distinctive flavor and texture. Several metabolic traits of LAB may significantly contribute to cereal-based products quality: antimicrobial activity, acidification and modification of the redox potential, formation of polysaccharides and oligopolysaccharides, and glutamine and glutamate metabolism (Gänzle, 2009). In addition, it is not secondary to consider the LAB influence on organoleptic properties (for instance volume, crumb texture, and a unique flavor). Although pasta is generally not considered for its aromatic properties, Beleggia et al. (2009) analyzed the chemical and volatile composition of semolina and pasta samples produced from four durum wheat cultivars, identifying 35 volatile compounds including aldehydes, ketones, alcohols, terpenes, esters, hydrocarbons, and a furan. These findings prove that semolina potentially releases volatile compounds that might affect the aroma of the pasta products. In particular, the authors observed quantitative and qualitative volatile compounds differences between semolina and pasta samples. During cooking, an increase in aldehyde content, the appearance of ketones, and a decrease in alcohol content were found (Beleggia et al., 2009). Recently, Beleggia et al. (2011) investigated the metabolite variations during industrial pasta processing (from semolina to dried pasta) for five different commercial products, evidencing that a number of metabolites undergo a transformation during pasta-making, depending on the processing conditions adopted. di Cagno et al. (2005) evaluated sensorial quality of pasta produced with a LAB-based biotechnological step: they did not found difference in odor and flavor, while slightly decreased stickiness and firmness were detected.

\section{NUTRITIONAL QUALITY, MICRONUTRIENTS, AND LAB CELL FACTORIES}

Fermentation can modify cereal matrix in a number of ways potentially increasing nutritional quality of the final products (Poutanen et al., 2009). The production of organic acids is responsible for a lower degree of starch gelatinization which would probably explain diminished starch digestibility, which leads to low glycemic responses (Poutanen et al., 2009). LAB may be employed to remove selected undesirable sugars or to produce numerous low-calorie sugars and oligosaccharides (Hugenholtz et al., 2002). In addition, the changes introduced by fermentation selectively influence the activity of certain enzymes, such as amylases, proteases, hemicellulases, and phytases (Poutanen et al., 2009). In particular, LAB phytases catalyze phytic acid hydrolysis (Lopez et al., 2000; De Angelis et al., 2003). Phytic acid has a negative impact on the bioavailability of divalent and trivalent mineral ions (Lopez et al., 2000; De Angelis et al., 2003). Additionally, the production of lactic acid by $\mathrm{LAB}$ and the consequent $\mathrm{pH}$ decrease improve mineral bioavailability (Poutanen et al., 2009). The concept of in situ fortification by bacterial fermentation provides the basis to enhance the nutritional value of food products and their commercial value. In recent years, a number of biotechnological processes have been explored to perform a more economical and sustainable vitamin production than that obtained via chemical synthesis (Burgess et al., 2009). By this approach, we developed a convenient, efficient and food-grade biotechnological strategy for the production of vitamin B2-enriched bread and pasta (Capozzi et al., 2011). The increasing number of sequenced LAB genomes (Klaenhammer et al., 2002) is changing our vision on the use of metabolic models for improving food fermentation and LAB cell factories performance in food industries (Smid et al., 2005). From gene to function, from microbial biodiversity to ecological lifestyle, from evolution to domestication: high-throughput techniques, next-generation tools, and systems biology approaches offer the opportunity to reconstruct the complete metabolic networks for high-throughput comprehensive models of cell bio-productions and starter robustness (Siezen et al., 2004; Guerzoni, 2010; Capozzi and Spano, 2011; Roy et al., 2011; Suzzi, 2011; Altermann, 2012; Diz et al., 2012).

\section{FUNCTIONAL APPLICATION}

Lactic acid bacteria may bioproduce functional molecules and/or modulate (stabilize or increase) levels and bioaccessibility of bioactive compounds. Here, a brief overview to appreciate the high innovation content taking into account the potential health implications: (i) LAB may improve the palatability of whole grain and fiber-rich products (Katina et al., 2005) associated with health 
benefits, such as enhanced regulation of blood glucose levels, reduced risk of diabetes, cardiovascular disease, and certain cancers (Jacobs et al., 1998; Liu et al., 2000; Pereira et al., 2002); (ii) LAB may modify the bran fraction of the grain (rich in fiber) in such a way that larger amounts of bran can be utilized in breads (Katina et al., 2005); (iii) LAB may contribute to produce novel, naturally fermented health-oriented products enriched in gamma-aminobutyric acid ( $\mathrm{Li}$ and Cao, 2010; Li et al., 2010); (iv) LAB may synthesize angiotensin I-converting enzyme (ACE)-inhibitory peptides (Rizzello et al., 2011); (v) LAB may produce non-digestible polysaccharides, or modify accessibility of the grain fiber complex to the gut microbiota (Poutanen et al., 2009; Garai-Ibabe et al., 2010; Elizaquível et al., 2011).

\section{THE GLUTEN-FREE ISSUE}

In reason of current trends, an important field of application of LAB-based biotechnology is the huge growing gluten-free (GF) market. This interesting niche requires high innovative contributes to solve the celiac disease issue, also in the pasta segment. There are two main routes to achieve this purpose: (i) the use of selected LAB to degrade gluten (Gobbetti et al., 2007) and (ii) the employ of particular LAB to increase the quality GF products (Moroni et al., 2009). The first strategy has been already applied to pasta manufacture (di Cagno et al., 2005): recent biotechnological evolution couple lactobacilli and fungal proteases to improve durum wheat semolina gluten degradation, maintaining cooking, and sensory properties higher that those of conventional gluten-free pasta (De Angelis et al., 2010). The second approach consider LAB "as 'burgeoning' cell factories for the delivering of functional biomolecules and food ingredients for the production of high quality GF cereal products" (Arendt et al., 2011), with the aim to improve texture, aroma, nutritional properties, health benefits and shelf life.

\section{FUTURE PERSPECTIVES}

The question "Which strains for which application?" (Gänzle, 2009) well summarizes the future directions in this applied biotechnological domain. Leroy and De Vuyst (2004) define a starter culture as "a microbial preparation of large numbers of cells of at least one microbial species to be added to a raw material

\section{REFERENCES}

Altermann, E. (2012). Tracing lifestyle adaptation in prokaryotic genomes. Front. Microbiol. 3:48. doi:10.3389/fmicb.2012.00048

Antognelli, C. (1980). The manufacture and applications of pasta as a food and as a food ingredient: a review. Int. J. Food Sci. Technol. 15, 125-145.

Arendt, E., Moroni, A., and Zannini, E. (2011). Medical nutrition therapy: use of sourdough lactic acid bacteria as a cell factory for delivering functional biomolecules and food ingredients in gluten free bread. Microb. Cell Fact. 10, S15.

Beleggia, R., Platani, C., Papa, R., Di Chio, A., Barros, E., Mashaba, C., Wirth, J., Fammartino, A., Sautter,

to produce a fermented food by accelerating and steering its fermentation process." In this specific application, the selection of starter strains becomes more difficult due to the non-fermented status of the given food matrix. In fact, a key matter is represented by the technological compatibility of the introduced microbial innovation. Satisfied this starting point, two aspects should be considered: (i) the introduced, possible advance has a multidimensional structure, in reason of the many facets of pasta quality perceived by consumers and of the different kind of process and product innovations; (ii) many metabolic traits that determine the performance of a starter culture in industrial practice are strain specific (Gänzle, 2009). The selection of appropriate strains with the successful combination of functional properties takes advantage of the wide LAB biodiversity and metabolic variety occurring in the sourdough ecosystems (Gänzle, 2009). In fact, the spontaneous food fermentations are carried out by mixed cultures, and result from the competition within the indigenous microbial consortium, in relation to a specific food substrate. Also in the design of starter culture, mixed culture food fermentations are of primary economic importance to introduce multivariate levels of innovation (Sabra et al., 2010). "The performance of such cultures is not the simple result of 'adding up' the individual single strain functionalities but is largely determined by interactions at the level of substrates, the exchange of metabolites and growth factors or inhibiting compounds" (Sabra et al., 2010).

We conclude by highlighting the interesting innovation potential introduced with the adoption of a biotechnological LAB-based step in pasta production. An exciting opportunity in a food sector that is often referred to as "low-tech" (Kirner et al., 2009). Intense applied research activities are needed to tailor the huge potential of LAB in bread sourdough to pasta-making process.

\section{ACKNOWLEDGMENTS}

This work was founded by the Italian Ministery for Development in the framework of the "Industria 2015 Bando Nuove Tecnologie per il Made in Italy - Realizzazione di una innovativa pasta alimentare funzionale arricchita di componenti bioattivi e probiotici." This paper is dedicated to the memory of our friend and colleague, Dr. Natale di Fonzo.

Capozzi, V., Menga, V., Digesu, A. M., De Vita, P., van Sinderen, D., Cattivelli, L., Fares, C., and Spano, G. (2011). Biotechnological production of vitamin B2-enriched bread and pasta. J. Agric. Food Chem. 59, 8013-8020.

Capozzi, V., and Spano, G. (2011). Food microbial biodiversity and "microbes of protected origin." Front. Microbiol. 2:237. doi:10.3389/fmicb.2011.00237

Corsetti, A., Lavermicocca, P., Morea, M., Baruzzi, F., Tosti, N., and Gobbetti, M. (2001). Phenotypic and molecular identification and clustering of lactic acid bacteria and yeasts from wheat (species Triticum durum and Triticum aestivum) sourdoughs of Southern Italy. Int. J. Food Microbiol. 64, 95-104.
Corsetti, A., and Settanni, L. (2007). Lactobacilli in sourdough fermentation. Food Res. Int. 40, 539-558.

Corsetti, A., Settanni, L., Chaves Lõpez, C., Felis, G. E., Mastrangelo, M., and Suzzi, G. (2007). A taxonomic survey of lactic acid bacteria isolated from wheat (Triticum durum) kernels and non-conventional flours. Syst. Appl. Microbiol. 30, 561-571.

De Angelis, M., Cassone, A., Rizzello, C. G., Gagliardi, F., Minervini, F., Calasso, M., Di Cagno, R., Francavilla, R., and Gobbetti, M. (2010). Mechanism of degradation of immunogenic gluten epitopes from Triticum turgidum L. var. durum by sourdough lactobacilli and fungal proteases. Appl. Environ. Microbiol. 76, 508-518. 
De Angelis, M., Gallo, G., Corbo, M. R., McSweeney, P. L. H., Faccia, M., Giovine, M., and Gobbetti, M. (2003). Phytase activity in sourdough lactic acid bacteria: purification and characterization of a phytase from Lactobacillus sanfranciscensis CB1. Int. J. Food Microbiol. 87, 259-270.

de Noni, I., and Pagani, M. A. (2010). Cooking properties and heat damage of dried pasta as influenced by raw material characteristics and processing conditions. Crit. Rev. Food Sci. Nutr. 50, 465-472.

De Vuyst, L., and Neysens, P. (2005). The sourdough microflora: biodiversity and metabolic interactions. Trends Food Sci. Technol. 16, 43-56.

De Vuyst, L., and Vancanneyt, M. (2007). Biodiversity and identification of sourdough lactic acid bacteria. Food Microbiol. 24, 120-127.

De Vuyst, L., Vrancken, G., Ravyts, F., Rimaux, T., and Weckx, S. (2009). Biodiversity, ecological determinants, and metabolic exploitation of sourdough microbiota. Food Microbiol. 26, 666-675.

di Cagno, R., de Angelis, M., Alfonsi, G., de Vincenzi, M., Silano, M., Vincentini, O., and Gobbetti, M. (2005). Pasta made from durum wheat semolina fermented with selected lactobacilli as a tool for a potential decrease of the gluten intolerance. J. Agric. Food Chem. 53, 4393-4402.

Diz, A. P., Martínez-Fernández, M., and Rolán-Alvarez, E. (2012). Proteomics in evolutionary ecology: linking the genotype with the phenotype. Mol. Ecol. 21, 1060-1080.

Elizaquível, P., Sánchez, G., Salvador, A., Fiszman, S., Dueñas, M. T., López, P., Fernández de Palencia, P., and Aznar, R. (2011). Evaluation of yogurt and various beverages as carriers of lactic acid bacteria producing 2-branched (1,3)- $\beta$-D-glucan. J. Dairy Sci. 94, 3271-3278.

Fuad, T., and Prabhasankar, P. (2010). Role of ingredients in pasta product quality: a review on recent developments. Crit. Rev. Food Sci. Nutr. 50, 787-798.

Gänzle, M. G. (2009). From gene to function: metabolic traits of starter cultures for improved quality of cereal foods. Int. J. Food Microbiol. 134, 29-36.

Gänzle, M. G., Vermeulen, N., and Vogel, R. F. (2007). Carbohydrate, peptide and lipid metabolism of lactic acid bacteria in sourdough. Food Microbiol. 24, 128-138.
Garai-Ibabe, G., Dueñas, M. T., Irastorza, A., Sierra-Filardi, E., Werning, M. L., López, P., Corbí, A. L., and Fernández de Palencia, P. (2010) Naturally occurring 2-substituted (1,3)-beta-D-glucan producing Lactobacillus suebicus and Pediococcus parvulus strains with potential utility in the production of functional foods. Bioresour. Technol. 101, 9254-9263.

Gobbetti, M., De Angelis, M., Corsetti, A., and Di Cagno, R. (2005). Biochemistry and physiology of sourdough lactic acid bacteria. Trends Food Sci. Technol. 16, 57-69.

Gobbetti, M., Giuseppe Rizzello, C., Di Cagno, R., and De Angelis, M. (2007). Sourdough lactobacilli and celiac disease. Food Microbiol. 24, 187-196.

Guerzoni, M. E. (2010). Human food chain and microorganisms: a case of co-evolution. Front. Microbiol. 1:106. doi: 10.3389/fmicb. 2010.00106

Hugenholtz, J., Sybesma, W., Groot, M. N., Wisselink, W., Ladero, V., Burgess, K., van Sinderen, D., Piard, J. -C., Eggink, G., Smid, E. J., Savoy, G., Sesma, F., Jansen, T., Hols, P., and Kleerebezem, M. (2002). Metabolic engineering of lactic acid bacteria for the production of nutraceuticals. Antonie Van Leeuwenhoek 82, 217-235.

Jacobs, D., Meyer, K., Kushi, L., and Folsom, A. (1998). Whole-grain intake may reduce the risk of ischemic heart disease death in postmenopausal women: the Iowa Women's Health Study. Am. J. Clin. Nutr. 68, 248-257.

Katina, K., Arendt, E., Liukkonen, K. -H., Autio, K., Flander, L., and Poutanen, K. (2005). Potential of sourdough for healthier cereal products. Trends Food Sci. Technol. 16, 104-112.

Kirner, E., Kinkel, S., and Jaeger, A. (2009). Innovation paths and the innovation performance of lowtechnology firms - an empirical analysis of German industry. Res. Policy 38, 447-458.

Klaenhammer, T., Altermann, E., Arigoni, F., Bolotin, A., Breidt, F., Broadbent, J., Cano, R., Chaillou, S., Deutscher, J., Gasson, M., van de Guchte, M., Guzzo, J., Hartke, A., Hawkins, T., Hols, P., Hutkins, R., Kleerebezem, M., Kok, J., Kuipers, O., Lubbers, M., Maguin, E., McKay, L., Mills, D., Nauta, A., Overbeek, R., Pel, H., Pridmore, D., Saier, M., van Sinderen, D., Sorokin, A., Steele, J., O'Sullivan, D., de Vos, W., Weimer, B., Zagorec, M., and
Siezen, R. (2002). Discovering lactic acid bacteria by genomics. Antonie Van Leeuwenhoek 82, 29-58.

Leroy, F., and De Vuyst, L. (2004). Lactic acid bacteria as functional starter cultures for the food fermentation industry. Trends Food Sci. Technol. 15, 67-78.

Li, H., and Cao, Y. (2010). Lactic acid bacterial cell factories for gammaaminobutyric acid. Amino Acids 39, 1107-1116.

Li, H., Qiu, T., Huang, G., and Cao, Y. (2010). Production of gammaaminobutyric acid by Lactobacillus brevis NCL912 using fed-batch fermentation. Microb. Cell Fact. 9, 85.

Liu, S., Manson, J. E., Stampfer, M. J., Hu, F. B., Giovannucci, E., Colditz, G. A., Hennekens, C. H., and Willett, W. C. (2000). A prospective study of whole-grain intake and risk of type 2 diabetes mellitus in US women. Am. J. Public Health 90, 1409--1415.

Lopez, H. W., Ouvry, A., Bervas, E., Guy, C., Messager, A., Demigne, C. and Remesy, C. (2000). Strains of lactic acid bacteria isolated from sour doughs degrade phytic acid and improve calcium and magnesium solubility from whole wheat flour. J. Agric. Food Chem. 48, 2281-2285.

Moroni, A. V., Dal Bello, F., and Arendt, E. K. (2009). Sourdough in glutenfree bread-making: an ancient technology to solve a novel issue? Food Microbiol. 26, 676-684.

Paramithiotis, S., Sofou, A., Tsakalidou, E., and Kalantzopoulos, G. (2007). Flour carbohydrate catabolism and metabolite production by sourdough lactic acid bacteria. World J. Microbiol. Biotechnol. 23, 1417-1423.

Pereira, M. A., Jacobs, D. R. Jr, Pins, J. J., Raatz, S. K., Gross, M. D., Slavin, J. L., and Seaquist, E. R. (2002). Effect of whole grains on insulin sensitivity in overweight hyperinsulinemic adults. Am. J. Clin. Nutr. 75, 848-855.

Poutanen, K., Flander, L., and Katina, K. (2009). Sourdough and cereal fermentation in a nutritional perspective. Food Microbiol. 26, 693-699.

Ravyts, F., and De Vuyst, L. (2011). Prevalence and impact of singlestrain starter cultures of lactic acid bacteria on metabolite formation in sourdough. Food Microbiol. 28, 1129-1139.

Ricciardi, A., Parente, E., Piraino, P., Paraggio, M., and Romano, P. (2005). Phenotypic characterization of lactic acid bacteria from sourdoughs for Altamura bread produced in Apulia (Southern Italy). Int. J. Food Microbiol. 98, 63-72.

Rizzello, C. G., Cassone, A., Di Cagno, R., and Gobbetti, M. (2011). Synthesis of angiotensin I-converting enzyme (ACE)-inhibitory peptides and $\gamma$-aminobutyric acid (GABA) during sourdough fermentation by selected lactic acid bacteria. J. Agric. Food Chem. 56, 6936-6943.

Roy, N. C., Altermann, E., Park, Z. A., and McNabb, W. C. (2011). A comparison of analog and NextGeneration transcriptomic tools for mammalian studies. Brief. Funct. Genomics 10, 135-150.

Russo, P., Beleggia, R., Ferrer, S., Pardo, I., and Spano, G. (2010). A polyphasic approach in order to identify dominant lactic acid bacteria during pasta manufacturing. Food Sci. Technol. 43, 982-986.

Sabra, W., Dietz, D., Tjahjasari, D., and Zeng, A. (2010). Biosystems analysis and engineering of microbial consortia for industrial biotechnology. Eng. Life Sci. 10, 407-421.

Salminen, S., Wright A. von., and Ouwehand, A. (2004). Lactic Acid Bacteria: Microbiological and Functional Aspects. Boca Raton: CRC Press

Scheirlinck, I., Van der Meulen, R., Van Schoor, A., Vancanneyt, M., De Vuyst, L., Vandamme, P., and Huys, G. (2007). Influence of geographical origin and flour type on diversity of lactic acid bacteria in traditional Belgian sourdoughs. Appl. Environ. Microbiol.73, 6262-6269.

Siezen, R. J., van Enckevort, F. H. J., Kleerebezem, M., and Teusink, B. (2004). Genome data mining of lactic acid bacteria: the impact of bioinformatics. Curr. Opin. Biotechnol. 15, 105-115.

Smid, E. J., van Enckevort, F. J. H., Wegkamp, A., Boekhorst, J., Molenaar, D., Hugenholtz, J., Siezen, R. J., and Teusink, B. (2005). Metabolic models for rational improvement of lactic acid bacteria as cell factories. $J$. Appl. Microbiol. 98, 1326-1331.

Suzzi, G. (2011). From wild strain to domesticated strain: the philosophy of microbial diversity in foods. Front. Microbiol. 2:169. doi:10.3389/fmicb.2011.00169

Troccoli, A., Borrelli, G. M., De Vita, P., Fares, C., and Di Fonzo, N. (2000). Mini review: durum wheat quality: a multidisciplinary concept. J. Cereal Sci. 32, 99-113.

Valerio, F., Favilla, M., De Bellis, P., Sisto, A., de Candia, S., and Lavermicocca, 
P. (2009). Antifungal activity of strains of lactic acid bacteria isolated from a semolina ecosystem against Penicillium roqueforti, Aspergillus niger and Endomyces fibuliger contaminating bakery products. Syst. Appl. Microbiol. 32, 438-448.

Van der Meulen, R., Scheirlinck, I., Van Schoor, A., Huys, G., Vancanneyt, M., Vandamme, P., and De Vuyst, L. (2007). Population dynamics and metabolite target analysis of lactic acid bacteria during laboratory fermentations of wheat and spelt sourdoughs. Appl. Environ. Microbiol. 73, 4741-4750.

Vogel, R. F., Knorr, R., Müller, M. R., Steudel, U., Gänzle, M. G., and Ehrmann, M. A. (1999). Nondairy lactic fermentations: the cereal world. Antonie Van Leeuwenhoek 76, 403-411.

Zhang, C., and Gänzle, M. G. (2010). Metabolic pathway of $\alpha$-ketoglutarate in Lactobacillus sanfranciscensis and Lactobacillus reuteri during sourdough fermentation. J. Appl. Microbiol. 109, 1301-1310.
Conflict of Interest Statement: The authors declare that the research was conducted in the absence of any commercial or financial relationships that could be construed as a potential conflict of interest.

Received: 10 February 2012; paper pending published: 20 February 2012; accepted: 26 February 2012; published online: 15 March 2012.

Citation: Capozzi V, Russo P, Fragasso $M$, De Vita $P$, Fiocco $D$ and Spano $G$ (2012) Biotechnology and pasta-making: lactic acid bacteria as a new driver of innovation. Front. Microbio. 3:94. doi: 10.3389/fmicb.2012.00094

This article was submitted to Frontiers in Microbiotechnology, Ecotoxicology and Bioremediation, a specialty of Frontiers in Microbiology.

Copyright (c) 2012 Capozzi, Russo, Fragasso, De Vita, Fiocco and Spano. This is an open-access article distributed under the terms of the Creative Commons Attribution Non Commercial License, which permits non-commercial use, distribution, and reproduction in other forums, provided the original authors and source are credited. 